\title{
Establishment of an in vitro transcription system for Peste des petits ruminant virus
}

\author{
Mohammad Yunus and Melkote S Shaila*
}

\begin{abstract}
Background: Peste-des-petits ruminants virus (PPRV) is a non segmented negative strand RNA virus of the genus Morbillivirus within Paramyxoviridae family. Negative strand RNA viruses are known to carry nucleocapsid (N) protein, phospho (P) protein and RNA polymerase ( $L$ protein) packaged within the virion which possess all activities required for transcription, post-transcriptional modification of mRNA and replication. In order to understand the mechanism of transcription and replication of the virus, an in vitro transcription reconstitution system is required. In the present work, an in vitro transcription system has been developed with ribonucleoprotein (RNP) complex purified from virus infected cells as well as partially purified recombinant polymerase (L-P) complex from insect cells along with N-RNA (genomic RNA encapsidated by N protein) template isolated from virus infected cells.

Results: RNP complex isolated from virus infected cells and recombinant L-P complex purified from insect cells was used to reconstitute transcription on N-RNA template. The requirement for this transcription reconstitution has been defined. Transcription of viral genes in the in vitro system was confirmed by PCR amplification of CDNAs corresponding to individual transcripts using gene specific primers. In order to measure the relative expression level of viral transcripts, real time PCR analysis was carried out. QPCR analysis of the transcription products made in vitro showed a gradient of polarity of transcription from $3^{\prime}$ end to $5^{\prime}$ end of the genome similar to that exhibited by the virus in infected cells.

Conclusion: This report describes for the first time, the development of an in vitro transcription reconstitution system for PPRV with RNP complex purified from infected cells and recombinant L-P complex expressed in insect cells. Both the complexes were able to synthesize all the mRNA species in vitro, exhibiting a gradient of polarity in transcription.
\end{abstract}

Keywords: Peste-des-petits ruminants virus (PPRV), Transcription reconstitution, RNA dependent RNA polymerase, Morbillivirus

\section{Background}

Peste-des-petits ruminants virus (PPRV), the causal agent of peste-des-petits ruminants (PPR) disease, belongs to the genus Morbillivirus within the Paramyxoviridae family. The genomes of paramyxoviruses encode six transcription units from which mRNAs coding for both structural and non-structural proteins are generated. Located at the 3' end of the genome is genomic promoter (GP) region also referred to as the leader region, which is followed by transcription units for N, P, M, F, H and $\mathrm{L}$ and ends in the antigenome promoter (AGP) or trailer region at the 5' end of the genome [1]. The genomic and antigenomic regions are known to play critical roles in initiation of transcription. $\mathrm{N}$ protein is essential

* Correspondence: shaila@mcbl.iisc.ernet.in

Department of Microbiology and Cell Biology, Indian Institute of Science, Bangalore 560012, India for encapsidation of the viral genomic RNA which acts as a template for transcription and replication by RNA dependent RNA polymerase ( $\mathrm{RdRp}$ ) complex. L protein itself is not able to recognize and carry out transcription or replication of viral genome encapsidated by $\mathrm{N}$ protein. $\mathrm{P}$ protein forms an essential component of RdRp and acts as a bridge between N-RNA and L protein [1,2]. For rinderpest virus, our earlier work has shown that the negative sense RNA genome encapsidated by $\mathrm{N}$ protein (N-RNA) along with phosphoprotein (P) and large polymerase (L) form the minimal transcription unit of the virus [3-5]. In order to study transcriptional and post-transcriptional activities associated with $\mathrm{L}$ protein, a reconstitution system of in vitro transcription is required. This has been achieved only for Rinderpest virus among morbilliviruses [5]. Further, employing a minigenome transcriptionreplication system, it has been shown that mutations in 
the GDNQ motif in L protein of rinderpest virus results in the inactivation of its polymerase activity in vitro as well as ex vivo [6].

The present study describes the establishment of an in vitro transcription system for PPRV employing purified RNP complex from virus infected cells as well as a reconstituted system employing recombinant L-P complex and $\mathrm{N}$-RNA template. Further, quantitation of transcripts made in vitro and in infected cells has been carried out.

\section{Results}

\section{Components of RNP complex from virus-infected cells}

The RNP complex purified from PPRV infected cells was analyzed on SDS-PAGE and visualized by coomassie brilliant blue staining (Figure 1a). The RNP complex consisted of 3 proteins corresponding to the expected molecular weights of $\mathrm{N}, \mathrm{P}$ and $\mathrm{L}$ proteins. The presence of $\mathrm{N}$ and $\mathrm{P}$ protein in RNP complex was confirmed by western blot analysis using antibody made against purified virus (Figure $1 \mathrm{~b}$ ). L protein could not be detected by western blotting as the L protein amount present in purified virus is very less in comparison to $\mathrm{N}$ and $\mathrm{P}$ proteins. The result showed that the RNP complex isolated from virus-infected cells contains the RNA polymerase constituents.

\section{Development of an in vitro transcription system with RNP complex}

The purified RNP complex was tested for its ability to synthesize viral mRNA in vitro. Incubation of purified RNP complex with $\alpha-{ }_{-}^{32}$ P-UTP and other NTPs resulted in a time dependent increase in incorporation of $\alpha-{ }^{32} \mathrm{P}-\mathrm{UMP}$ into TCA insoluble radioactivity (Figure 2a) suggesting that the purified RNP complex is active and is able to synthesize mRNA. RNP mediated transcription was maximal at $2 \mathrm{~h}$ of incubation at $30^{\circ} \mathrm{C}$. The in vitro RNA synthesis depended on viral proteins since RNA synthesis increased linearly with the increasing concentration of RNP complex (Figure 2b).

\section{RNP complex synthesizes all the gene specific transcripts} in vitro

In order to investigate if RNP complex could produce authentic copies of all viral mRNA, the in vitro transcription reaction was carried out with unlabelled rNTPs. Isolated RNA was converted to cDNA using oligo (dT) primer. The synthesized cDNA was used for PCR amplification of all the six genes of PPRV with gene specific primers $\mathrm{m}$ (Additional file 1: Table S1). Amplified DNA for N, P and $\mathrm{M}$ genes could be detected upon one round of PCR where as for F, $\mathrm{HN}$ and L genes, re amplification of primary PCR

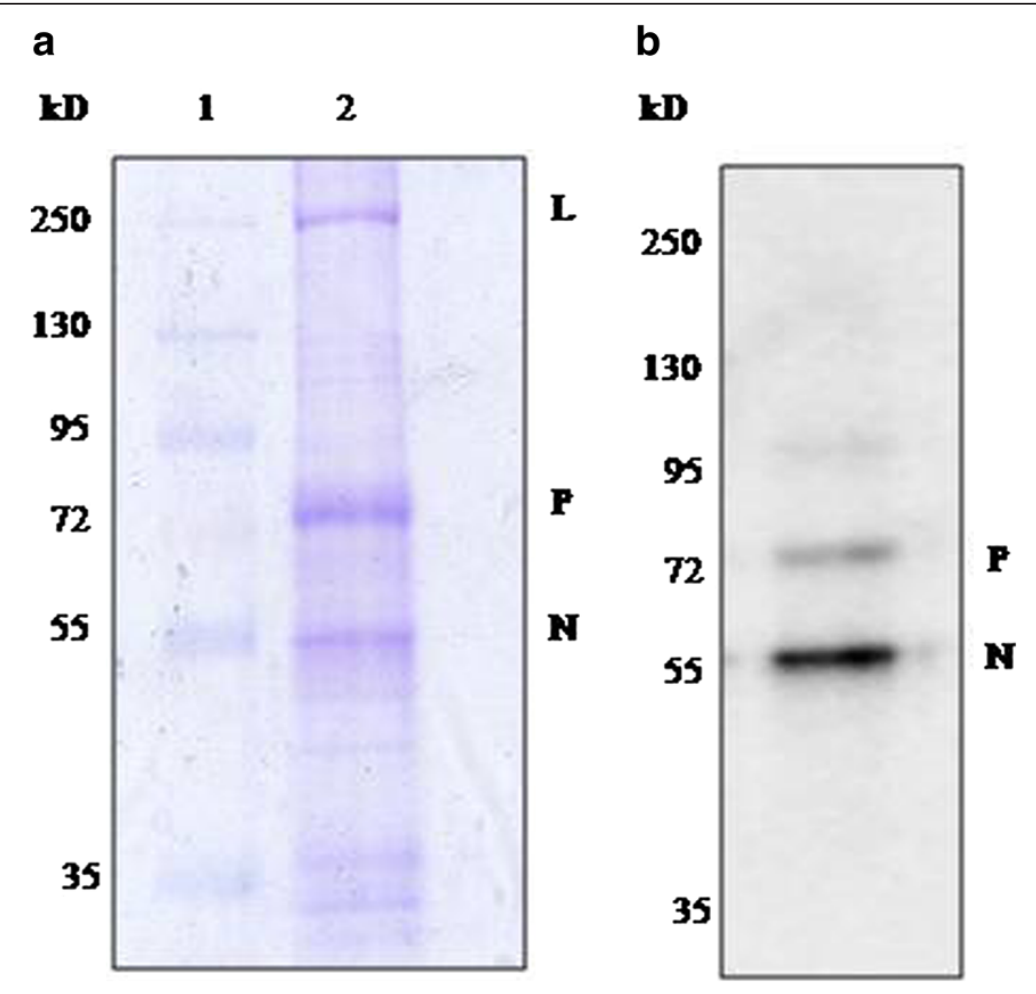

Figure 1 Protein composition of purified RNP complex from disrupted virus: (a) coomassie staining of RNP complex run on 8\% SDSPolyacrylamide gel. Lane 1 molecular weight marker (\#SM1811, Fermentas), lane 2, $10 \mu \mathrm{g}$ of RNP complex. (b) Western blot of RNP complex with rabbit polyclonal antibody against purified virus (1:5000). 

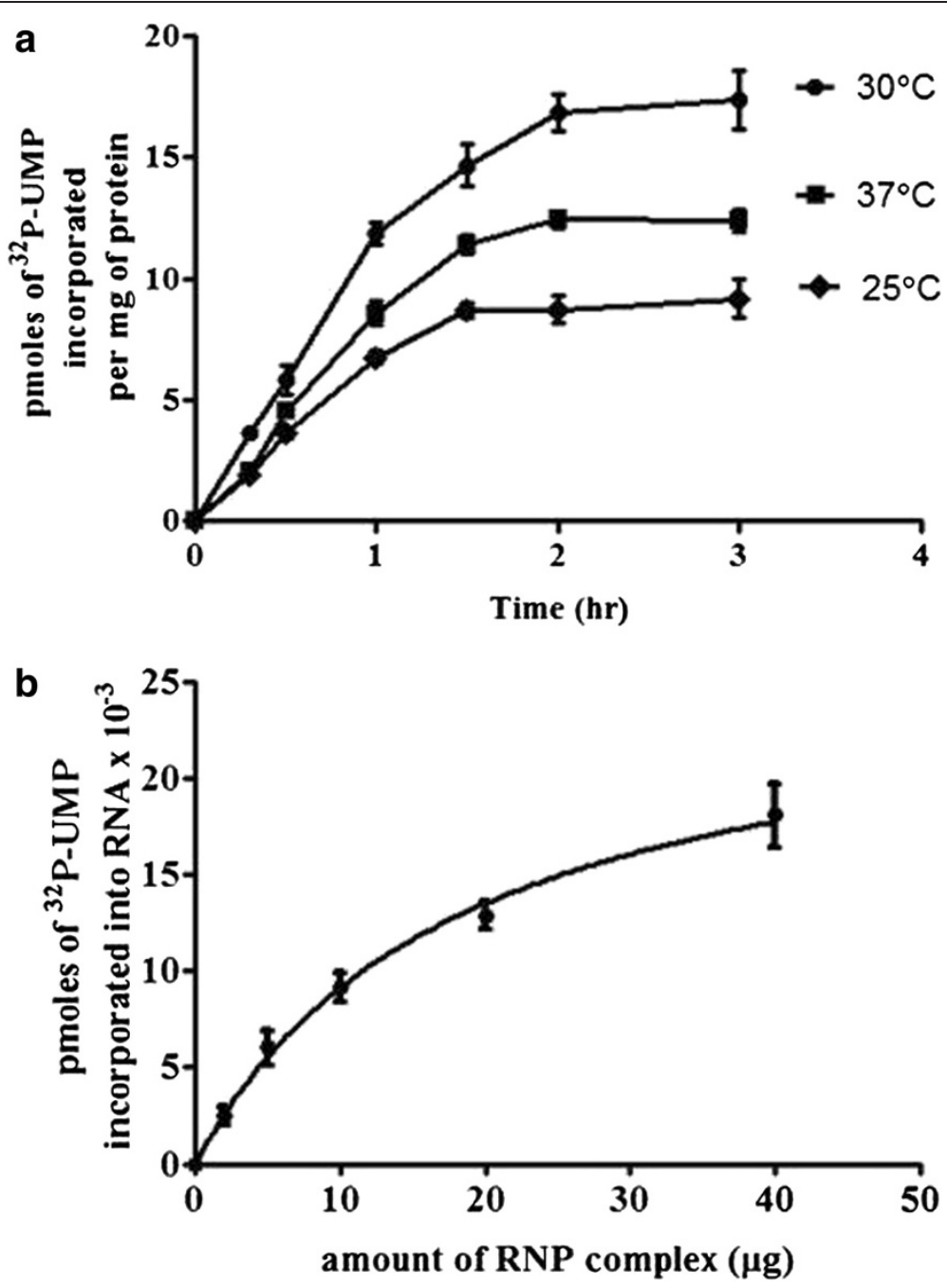

Figure 2 (a) in vitro transcription with RNP complex-Time kinetics of RNA synthesis. Transcription reaction mixture containing $20 \mu \mathrm{g}$ of RNP complex purified from PPR infected Vero cells were incubated at 25,30 and $37^{\circ} \mathrm{C}$ for different times. The incorporation of ${ }^{32} \mathrm{P}-\mathrm{UMP}$ into RNA was monitored by measuring TCA insoluble radioactivity. Transcription reaction in the absence of RNP complex was used as control. (b) in vitro transcription with RNP complex-dependency on protein concentration. Transcription reaction mixtures containing different amounts of RNP complex were incubated at $30^{\circ} \mathrm{C}$ for two hours.

product was necessary in order to detect by ethidium bromide staining (Figure 3a).

The data showed that in vitro transcription reaction with RNP complex resulted in the synthesis of all the transcripts of PPRV. For measurement of transcripts made in virus infected cells, RNA was isolated from PPRV infected Vero cells and processed for cDNA synthesis and analyzed by PCR (Figure 3b). The size of PCR products obtained from ex vivo and in vitro experiments were identical validating the authenticity of the in vitro system.

\section{In vitro reconstitution of transcription with recombinant} (L-P) complex and N-RNA

To establish the in vitro reconstitution system for PPRV, polymerase free N-RNA complex was purified from virus infected Vero cells by $\mathrm{CsCl}$ density gradient centrifugation. The purified N-RNA complex contained N protein (Figure 4a). The identity of protein was confirmed by western blotting with an antibody made against recombinant $\mathrm{N}$ protein of PPRV (Figure 4b). Recombinant polymerase complex (L-P) was partially purified from Sf 21 cells co-infected with recombinant baculoviruses expressing $\mathrm{L}$ and $\mathrm{P}$ proteins by sucrose density gradient centrifugation. The presence of $\mathrm{P}$ protein in different fractions of the gradient was confirmed by western blotting with P specific antibody [7]. Fractions showing P protein were pooled. Immunoprecipitation of the $\mathrm{r}(\mathrm{L}-\mathrm{P})$ complex with anti-P antibody followed by western blot analysis for $\mathrm{L}$ protein using anti-L domain III (1717-2183 aa) antibody showed the presence of L as (L-P) complex (Figure 4d). 


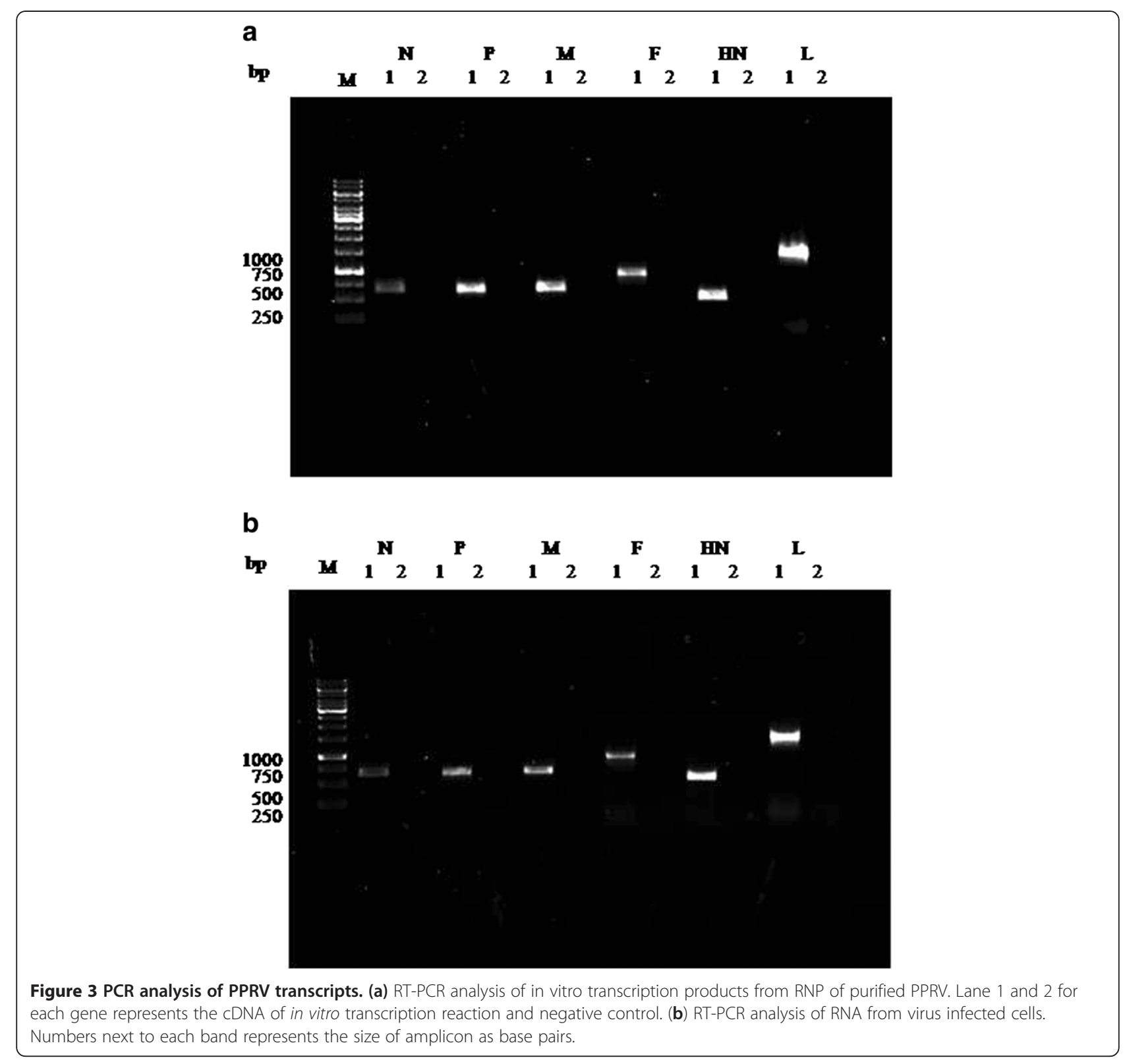

N-RNA complex was incubated with partially purified $r(\mathrm{~L}-\mathrm{P})$ complex in the presence of $\alpha-{ }^{32} \mathrm{P}-\mathrm{UTP}$ and other NTPs at $30^{\circ} \mathrm{C}$. The time course of incorporation of ${ }^{32} \mathrm{P}$-UMP into RNA is shown in Figure 5a. Increasing the concentration of $r(\mathrm{~L}-\mathrm{P})$ complex resulted in a linear increase in the amount of ${ }^{32} \mathrm{P}$-UMP incorporation (Figure $5 \mathrm{~b}$ ). The data showed that the incubation of polymerase free N-RNA complex with $\mathrm{r}(\mathrm{L}-\mathrm{P})$ complex results in the synthesis of mRNA in the in vitro transcription reaction. Reaction with N-RNA alone was unable to support RNA synthesis. In order to investigate the synthesis of all viral mRNA in the reconstituted system, isolated RNA from in vitro transcription reaction was converted to cDNA using oligo (dT) primer so that only authentic mRNA copies having poly (A) tail should get amplified. The cDNA was used for amplification by using gene specific PCR. The results showed (data not shown) that in vitro transcription reaction with purified components resulted in the synthesis of all the mRNAs of the virus.

\section{Quantification of transcripts synthesized by RNP and by} the recombinant L-P complex

In order to assess if synthesis of mRNA follows a gradient of polarity in the reconstituted system also, in vitro transcription followed by quantitative RT-PCR was carried 
b

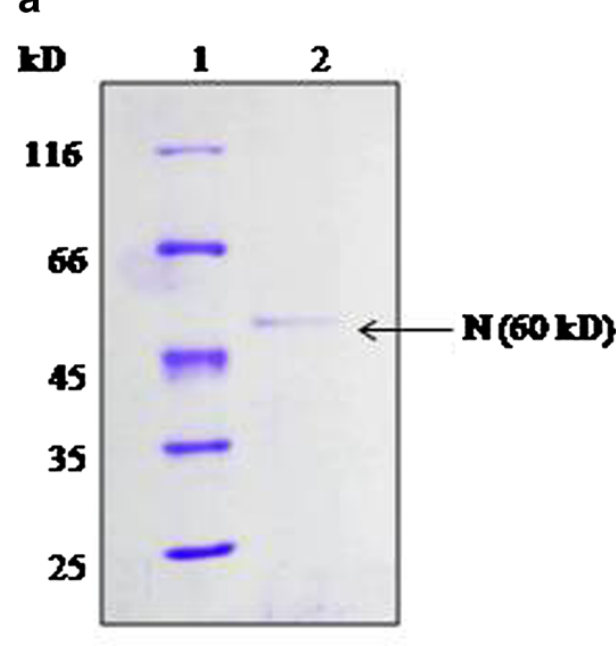

kD

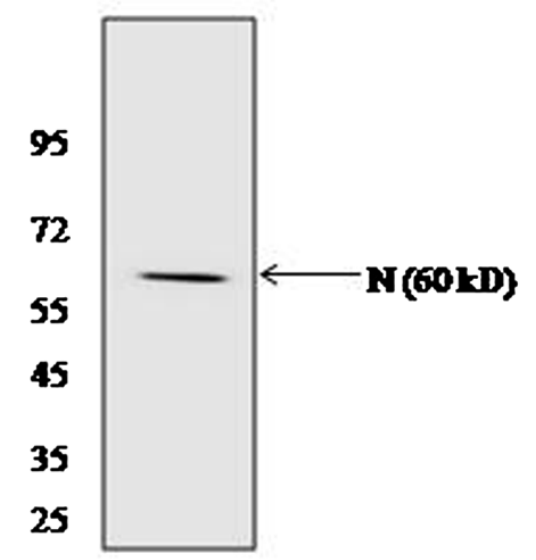

WB: aPPRN

d

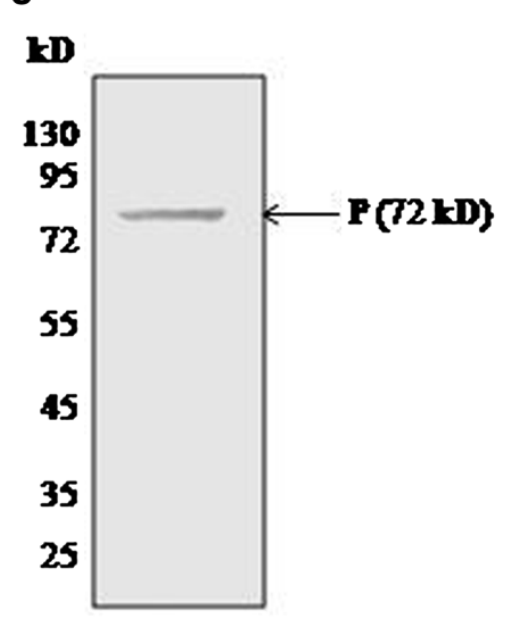

WB: aPiR-P
kD

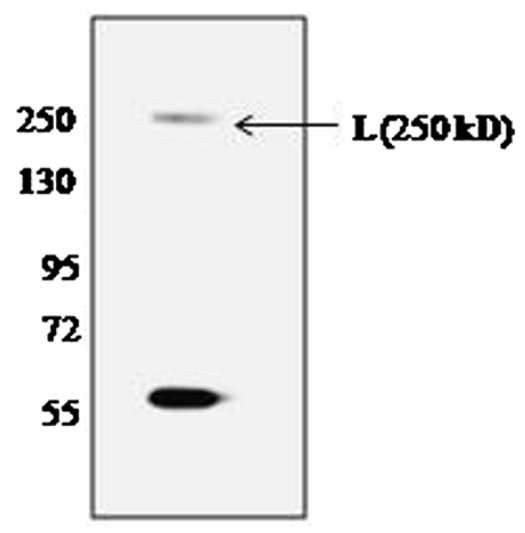

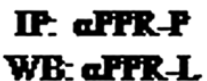

Figure 4 (a) N RNA complex of PPRV was purified from virus infected vero cells. Coomassie stained gel of purified PPR N RNA complex, lane 1 marker, lane $2 \mathrm{~N}$-RNA. (b) Presence of N protein was confirmed by western blot using antibody against recombinant N protein of PPRV (1:4000) [19]. (c) $20 \mu \mathrm{g}$ of partially purified recombinant (L-P) complex was subjected to western blot analysis for P protein with polyclonal antibody to recombinant P protein (1:4000) [7]. (d) To confirm L protein presence in partially purified L-P complex, $300 \mu \mathrm{g}$ of sample was immunoprecipitated using anti $P$ antibody and western blotting was done using an antibody against domain III of bacterially expressed $L$ protein of PPRV (1:5000). The bottom band in the panel $d$ represents the heavy chain of immunoglobulin used in pull down experiment.

out. To be able to compare the levels of expression of different genes, primers were made to produce amplicon size very close to each other (150-160 bp). To test the efficiency of primer pairs for all the six genes of PPRV, the genomic RNA from purified virus was isolated and converted to cDNA with gene specific primer mix or random hexamer. Addition of equimolar amounts of cDNAs to real time PCR reaction mix resulted in a amplification curve whose threshold cycle values were very close to each other for the six genes.(data not shown) This result was identical for cDNA generated by random hexamer or gene specific primers. A standard curve with 10 fold serial dilution $\left(10^{1}\right.$ to $\left.10^{5}\right)$ of $\mathrm{N}$ gene plasmid DNA was made. The standard curve resulted in a slope of -3.42 with $r^{2}$ value of 0.98 .

In order to determine the relative levels of different mRNAs made in the in vitro reconstituted system, the cDNA made from in vitro transcription reaction was analyzed by real time PCR. Since the source of cDNA for all genes was one (either from in vitro transcription reaction 

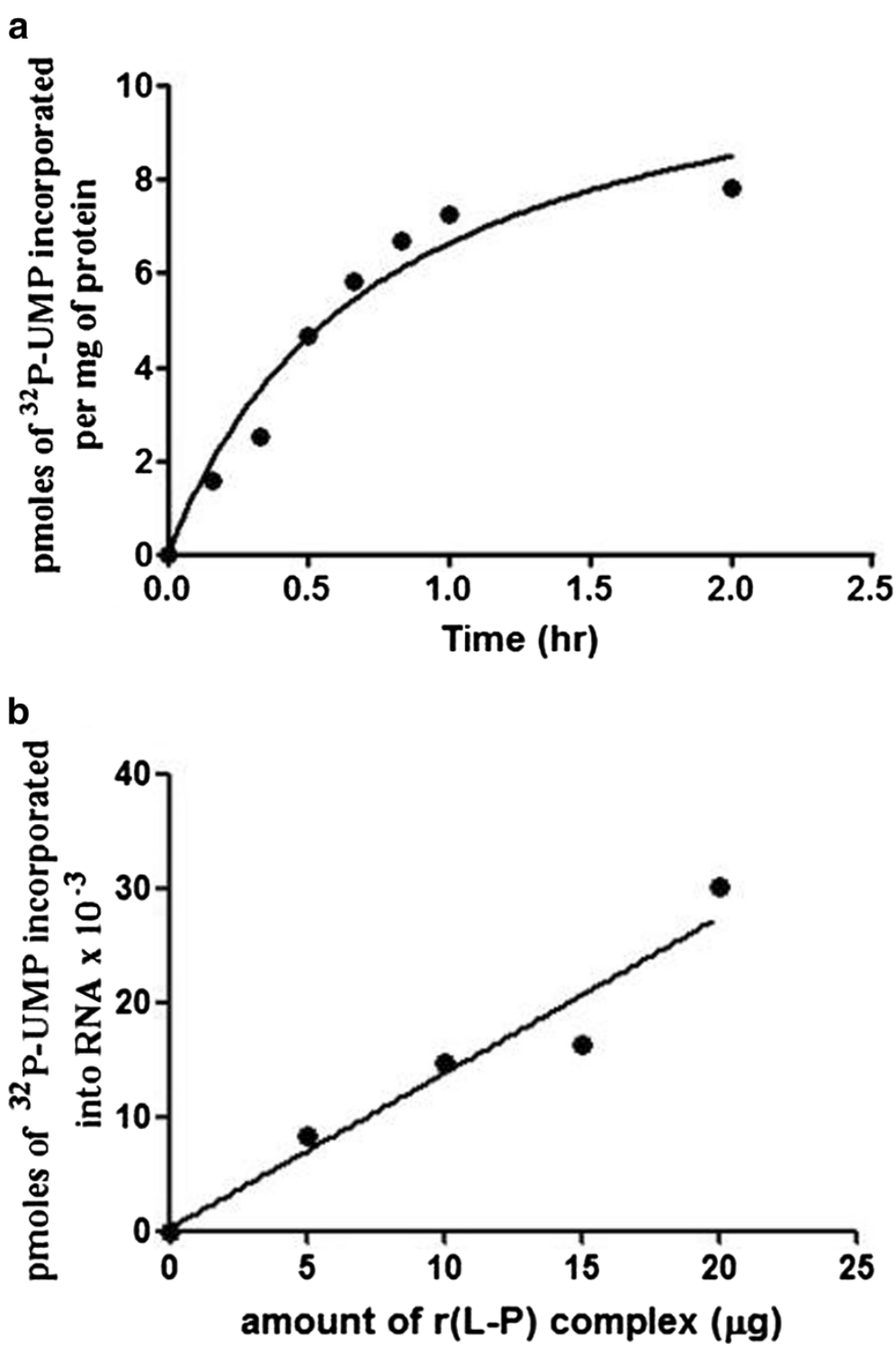

Figure 5 in vitro transcription with recombinant L-P complex. (a) Time kinetics. Transcription reaction mixture containing 10 $\mu$ g of $r(L-P)$ complex purified from Sf 21 cells were incubated at $30^{\circ} \mathrm{C}$ for the indicated time. The incorporation of ${ }^{32} \mathrm{P}-\mathrm{UMP}$ in RNA was monitored by TCA precipitation. A parallel reaction with N-RNA alone was carried out as control. Data represents the average of two independent experiments. (b) Enzyme concentration dependency of RNA synthesis.

or from infected cells), a master mix with all reagents except primers was made to ensure the presence of equal amount of cDNA for individual reaction. The result of real time PCR was analyzed for relative expression of different genes. The data in Figure 6 shows a gradient of polarity in transcription from 3' end of the genome towards 5 ' end with the highest transcription of $\mathrm{N}$ gene followed by $\mathrm{P}, \mathrm{M}, \mathrm{F}, \mathrm{HN}$ and $\mathrm{L}$ gene. The transcription level for $\mathrm{L}$ was around 80 fold lesser than that of the $\mathrm{N}$ gene $(\mathrm{N}>>>\mathrm{P}>>\mathrm{M}>\mathrm{F}>\mathrm{HN}>>>\mathrm{L}$ ) (Figure 6). The results were normalized against the least expressed gene of the virus, $\mathrm{L}$ gene, and plotted as fold change. To compare the transcripts made in the in vitro reconstituted system with the transcript profile within the infected cells, total RNA was isolated from PPRV infected Vero cells and converted to cDNA using oligo (dT) primer. The real time PCR result is comparable to that for in vitro synthesized mRNA (Figure 6) suggesting the polar gradient of transcription in the infected cells as well as in the in vitro reconstituted system. The copy numbers of each gene synthesized in infected cells as well as in the in vitro reconstitution were determined. Although the quantitative values of copy 


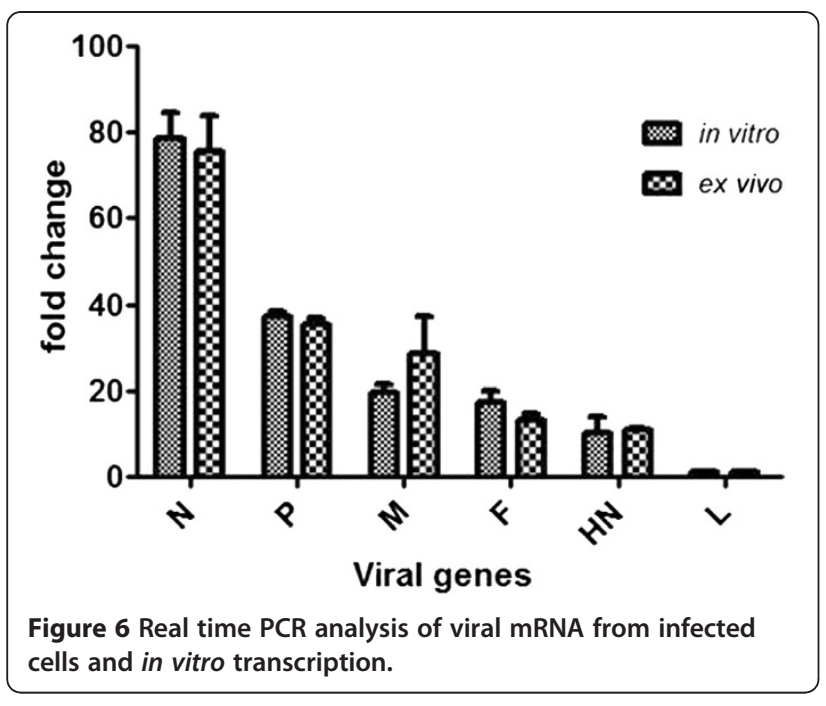

number per cell were different from copy numbers made in the in vitro transcription reaction, the pattern of gene expression in infected cells and in the in vitro transcription reaction was similar (Figure $7 \mathrm{a}$ and $\mathrm{b}$ ). The data given in Figure 7c shows that the $\mathrm{N}$ transcript represents almost
$50 \%$ of the transcripts synthesized in infected cells as well as in the in vitro transcription reconstitution reaction.

\section{Discussion}

The work described in the present study is the first demonstration of in vitro transcription reconstitution system for PPRV using RNP complex purified from infected cells as well as recombinant L-P complex purified from insect cells. The RNP complex isolated from infected cells is composed of $\mathrm{N}$ protein encapsidating the viral genome, $\mathrm{L}$ and $\mathrm{P}$ proteins which form the polymerase complex as shown for rinderpest virus [3] measles virus [8] and other members of mononegavirales order such as rabies virus, VSV, Sendai virus [9-11]. The RNP complex of PPRV is active in synthesizing RNA in the in vitro reconstituted system. Earlier work with L protein of different negative strand RNA viruses has revealed that other than polymerase function, L protein is involved in elongation, capping, cap methylation, polyadenylation and also possesses kinase activity $[1,2]$. With the establishment of the reconstituted system for PPRV, it would be possible to demonstrate the multifunctional activities of L protein of PPRV. In the earlier reported work with rinderpest virus, human respiratory syncytial virus and measles virus, L mRNA was not detected by Northern blotting $[3,8,12]$. In the present

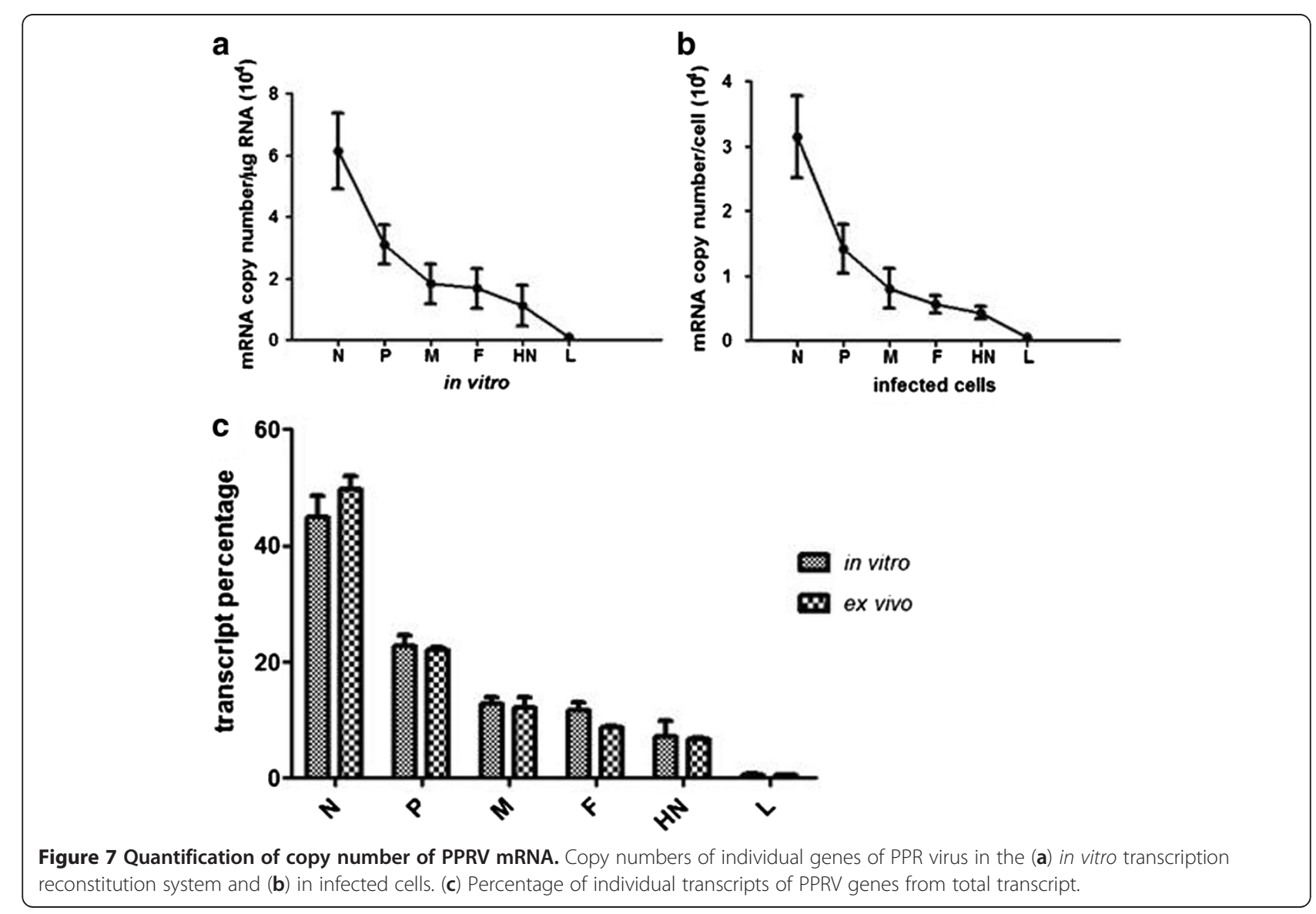


work, the synthesis of $\mathrm{L}$ transcript could be detected with the use of highly sensitive qPCR method. Further, to refine the in vitro reconstitution system for PPRV, recombinant L-P complex was expressed and purified from insect cells as has been done for Sendai and rinderpest virus $[5,13]$. The purified polymerase complex from insect cells when provided with N-RNA resulted in the synthesis of viral mRNA in the in vitro reconstituted system.

Relative quantification of virus specific mRNAs synthesized in vitro as well as ex vivo by real time PCR showed a distinct polar gradient of transcription from 3 ' end to 5' end of the genomic RNA. The results showed that $\mathrm{N}$ gene present at the 3' end of the genome is the highest transcribed gene whereas $\mathrm{L}$ gene present at the end of genome is the least (Figure 6 and 7). These results are in accordance with results reported for HPIV-3 and measles virus using in vitro transcription system $[14,15]$ as well as gene expression levels of measles virus in infected cells [16,17]. Analysis of real time PCR data revealed that the polarity of gene expression in infected cells and in the in vitro system follow similar pattern of gene expression. Copy number analysis of the transcripts from in vitro reconstitution and from infected cells although differ in their values the relative level of each gene with respect to $\mathrm{N}$ gene is similar in both the systems. These results support the single entry stop start model of viral transcription. The synthesis of P mRNA level is $50 \%$ of the $\mathrm{N}$ mRNA suggesting that after the completion of $\mathrm{N}$ gene transcript, the polymerase is able to successfully initiate P mRNA synthesis only once out of two attempts. Likewise polymerase is able to reach the end of the genome to synthesize L gene mRNA only once out of 75 attempts. These results are similar to the results obtained for measles virus $[15,17]$. The measurement of relative abundance of transcripts has revealed that $50 \%$ of the viral transcript is constituted by $\mathrm{N}$ gene mRNA and rest $50 \%$ by all the 5 remaining mRNAs.

The present work constitutes the first report of isolation of active transcription complex from PPRV infected cells as well as the in vitro reconstitution of transcription employing recombinant $\mathrm{L}$ and $\mathrm{P}$ proteins on isolated $\mathrm{N}$-RNA template. Using the defined system, it is now feasible to test the post transcriptional modification activities associated with the L protein of PPRV.

\section{Materials and methods}

\section{Cells and viruses}

Vero cells are grown in Dulbecco's modified essential medium (DMEM) supplemented with $10 \%$ fetal calf serum. PPRV (PPRV/Sungri/1996, obtained from IVRI, Mukteswar) isolate was used to infect Vero cells and the virus was purified according to Gopinath and Shaila [5] from culture supernatant. Spodoptera frugiperda (Sf 21), an insect cell line originally obtained from ATCC (USA) was supplied by National Center for Cell Sciences
(NCCS), Pune, India and is being maintained in the laboratory. Recombinant baculovirus expressing $\mathrm{P}$ protein was earlier generated in the lab [7]. Recombinant baculovirus expressing $\mathrm{L}$ protein was generated from $\mathrm{L}$ gene clone of PPRV Tu00 (generously provided by late Dr. T. Barrett, Institute of Animal Health, Pirbright, UK) [18].

\section{Purification of RNP complex from infected cells}

RNP complex was isolated from virus infected cells according to Ghosh et al. [3]. Briefly Vero cells monolayer were infected with PPRV at a moi of 5 and incubated for $72-84$ hrs at $37^{\circ} \mathrm{C}$ when approximately $60-70 \%$ cytopathic effect was observed. The cells were washed with ice cold PBS and scraped off with the help of cell scraper. The cell pellet was collected by centrifugation at $2000 \mathrm{rpm}$ for 10 minute at $4{ }^{\circ} \mathrm{C}$. Cells were re suspended in hypotonic lysis buffer (50mM HEPES pH 8.0, 50mM NH4Cl, 7mM KCI, $4.5 \mathrm{mM}$ magnesium acetate, $1 \mathrm{mM}$ dithiothreitol and $0.1 \%$ Triton X-100). The cells were allowed to swell for $5 \mathrm{~min}$ on ice and lysed by sonication. The homogenate was clarified by centrifugation at $12,000 \mathrm{~g}$ for 10 minute at $4^{\circ} \mathrm{C}$. The supernatant fluid was collected and centrifuged through 4 $\mathrm{ml}$ of $50 \%$ glycerol in the lysis buffer (described above) for $2 \mathrm{~h}$ at $32000 \mathrm{rpm}$ in a Beckman SW41 rotor at $4^{\circ} \mathrm{C}$. The pellet containing RNP complexes was suspended in $1 \mathrm{x}$ transcription buffer (50mM HEPES $[\mathrm{pH} \quad 8.0], 4.5 \mathrm{mM}$ MgOAc, $50 \mathrm{mM} \mathrm{NH} 4 \mathrm{Cl}, 7 \mathrm{mM} \mathrm{KCl}, 1 \mathrm{mM}$ dithiothreitol and $1 \mathrm{mM}$ spermidine).

\section{Preparation of N-RNA template}

N-RNA was prepared from PPRV infected Vero cells according to Gopinath and Shaila [5]. In brief, PPRV infected Vero cells were lysed in buffer containing $50 \mathrm{mM}$ Tris- $\mathrm{HCl}$ (pH 8.0), $150 \mathrm{mM} \mathrm{NaCl}, 0.6 \%$ NP40, $0.4 \%$ TritonX100 and 1mM DTT. The cell lysate was clarified and EDTA was added to a final concentration of $6 \mathrm{mM}$. The lysate was layered on a 20 to $40 \%$ (wt/wt) $\mathrm{CsCl}$ gradient and centrifuged at $200,000 \mathrm{X} \mathrm{g}$ for $2 \mathrm{hr}$ at $12^{\circ} \mathrm{C}$ in an SW41 rotor. N-RNA obtained was again purified on $\mathrm{CsCl}$ gradient. The N-RNA band was diluted 10 folds in TE buffer and centrifuged at $200,000 \mathrm{X}$ g at $4^{\circ} \mathrm{C}$ for $2 \mathrm{hr}$ in an SW41 rotor. Finally, the N-RNA was sedimented through $40 \%$ glycerol in 50mM HEPES-KOH (pH 8.0), $50 \mathrm{mM}$ $\mathrm{NaCl}, 0.2 \% \mathrm{NP} 40$ and $1 \mathrm{mM}$ DTT onto a $100 \mu \mathrm{l}$ cushion of $100 \%$ glycerol and stored in aliquots at $-70^{\circ} \mathrm{C}$ at a concentration of $0.6 \mu \mathrm{g} / \mu \mathrm{l}$. The presence of N-RNA was confirmed by western blotting using antibody against recombinant PPRV N protein [19].

\section{Partial purification of L-P complex}

Recombinant (L-P) complex of PPRV was partially purified from infected Sf 21 cells as described for rinderpest virus [5] and sendai virus [13]. Briefly Sf 21 cells $\left(2 \times 10^{7}\right)$ 
were co-infected with recombinant baculoviruses expressing PPRV L and P proteins at a moi of 10 and 2 respectively. After $48 \mathrm{hrs}$ post infection cells were washed once in PBS. Cells were suspended in $4 \mathrm{ml}$ of lysis buffer containing $50 \mathrm{mM}$ Tris- $\mathrm{HCl}(\mathrm{pH} 8.0), 500 \mathrm{mM} \mathrm{NaCl}, 0.5 \%$ Triton $\mathrm{X} 100,1 \mathrm{mM}$ DTT, $5 \mathrm{mM} \mathrm{MgCl} 2$ and $1 \mathrm{X}$ protease inhibitor cocktail. After lysis by three rounds of freeze thaw cycles, the clarified lysate $(4 \mathrm{ml})$ was layered onto a linear 5 to $20 \%$ glycerol gradient $(1 \mathrm{ml}$ of $20 \%$ glycerol and $2 \mathrm{ml}$ each of 5,10 and $15 \%$ glycerol) prepared in buffer containing $50 \mathrm{mM}$ HEPES- $\mathrm{KOH}$ (pH 8.0), $150 \mathrm{mM} \mathrm{NH}_{4} \mathrm{Cl}, 5 \mathrm{mM}$ $\mathrm{MgCl} 2$, and $1 \mathrm{mM}$ DTT. Gradients were centrifuged at $150,000 \mathrm{~g}$ in SW41 rotor for $36 \mathrm{hr}$ at $4^{\circ} \mathrm{C}$. Fractions $(1.2 \mathrm{ml})$ were collected from the top of the tube. $20 \mu$ l fractions were electrophoresed on 10\% SDS polyacrylamide gel followed by coomassie staining as well as western blotting for the detection of $\mathrm{P}$ protein with anti-PPRV P antibody [7].

\section{Reconstitution of in vitro transcription}

In vitro transcription assay using either viral RNP or recombinant L-P complex was carried out according to the method described for rinderpest virus [3,5]. Briefly, in vitro transcription reaction was carried out in $100 \mu \mathrm{l}$ reaction mixture having 50mM HEPES (N-2-hydroxyethylpiperazine-N'-2-ethanesulfonic acid) $\mathrm{pH} \quad 8.0, \quad 50 \mathrm{mM}$ $\mathrm{NH}_{4} \mathrm{Cl}, 7 \mathrm{mM} \mathrm{KCl}, 4.5 \mathrm{mM}$ magnesium acetate, $1 \mathrm{mM}$ dithiothreitol, $1 \mathrm{mM}$ each ATP, GTP, CTP and $100 \mu \mathrm{M}$ UTP, $10 \mu \mathrm{Ci}$ of $\alpha{ }^{32} \mathrm{P}$-UTP (specific activity $3000 \mathrm{Ci} / \mathrm{mmol}$, BRIT, India), $5 \mu \mathrm{g}$ per $\mathrm{ml}$ of actinomycin $\mathrm{D}$, and $1 \mathrm{mM}$ spermidine at $30^{\circ} \mathrm{C}$ with $20 \mu \mathrm{g}$ of RNP complex from infected cells or $10 \mu \mathrm{g} r(\mathrm{~L}-\mathrm{P})$ complex from insect cells. $10 \mu \mathrm{l}$ of reaction mixture was precipitated with $10 \%$ trichloroacetic acid on glass fibre filters. The filters were washed with $10 \%$ ice cold TCA three times followed by $5 \%$ ice cold TCA and finally with $70 \%$ ethanol and dried. The TCA insoluble radioactivity was measured in a liquid scintillation spectrometer.

\section{Analysis of transcription products by RT-PCR and real time PCR}

For analysis of transcripts, in vitro transcription reaction was carried for two hours without radio labeled NTPs. RNA was extracted using Trizol (Sigma)-chloroform and precipitated with ethanol. The in vitro synthesized RNA was converted to cDNA using oligo (dT) primer and RevertAid $^{\mathrm{TM}}$ Premium Reverse transcriptase. For analysis of transcripts synthesized ex vivo, Vero cells were infected with 5 moi of PPRV and RNA was isolated by SV total RNA isolation kit, Promega as per manufacturers instruction and converted to cDNA as mentioned above. The cDNAs of in vitro reconstitution system were employed for real time PCR carried out using Finnzyme DyNAmoTM HS SYBR green qPCR kit. qPCR was done using Applied Biosystems 7900 HT real time PCR machine. To quantify the copy number of transcripts made in vitro and in infected cells, a standard curve was made by using 10 fold dilution of plasmid encoding $\mathrm{N}$ gene. Since all the primers were working with equal efficiency, the above standard curve was used to quantify all the six genes. The in vitro transcription data was expressed as copy numbers per micro gram and ex vivo data as copy number per cell.

\section{Additional file}

Additional file 1: Table S1. List of the primer for RT-PCR analysis. Table S2. List of the primers for real time PCR analysis.

\section{Competing interests}

The authors declare that they have no competing interests.

\section{Authors' contributions}

MY carried out the experiments; MSS conceived the work and participated in design and coordination of the work. Both authors were involved in drafting the manuscript and approved the final manuscript.

Received: 27 June 2012 Accepted: 30 November 2012

Published: 5 December 2012

\section{References}

1. Curran J, Kolakofsky D: Replication of paramyxoviruses. Adv Virus Res 1999, 54:403-422.

2. Sedlmeier $R$, Neubert WJ: The replicative complex of paramyxoviruses: structure and function. Adv Virus Res 1998, 50:101-139.

3. Ghosh A, Joshi VD, Shaila MS: Characterization of an in vitro transcription system from rinderpest virus. Vet Microbiol 1995, 44:165-173.

4. Ghosh A, Nayak R, Shaila MS: Synthesis of leader RNA and editing of $P$ mRNA during transcription by rinderpest virus. Virus Res 1996, 41:69-76.

5. Gopinath $M$, Shaila MS: Recombinant $L$ and $P$ protein complex of Rinderpest virus catalyses mRNA synthesis in vitro. Virus Res 2008, 135:150-154.

6. Chattopadhyay A, Raha T, Shaila MS: Effect of single amino acid mutations in the conserved GDNQ motif of $L$ protein of Rinderpest virus on RNA synthesis in vitro and in vivo. Virus Res 2004, 99:139-145.

7. Saikia P, Shaila MS: Identification of functional domains of phosphoproteins of two morbilliviruses using chimeric proteins. Virus Genes 2008, 37:1-8.

8. Ray J, Fujinami RS: Characterization of in vitro transcription and transcriptional products of measles virus. J Virol 1987, 61:3381-3387.

9. Takagi T, Muroya K, Iwama M, Shioda T, Tsukamoto T, Mizumoto K: In vitro mRNA synthesis by Sendai virus: isolation and characterization of the transcription initiation complex. J Biochem 1995, 118:390-396.

10. Franze-Fernandez MT, Banerjee AK: In vitro RNA transcription by the New Jersey serotype of vesicular stomatitis virus. I. Characterization of the mRNA species. J Virol 1978, 26:179-187.

11. Banerjee AK: The transcription complex of vesicular stomatitis virus. Cell 1987, 48:363-364.

12. Huang $Y T$, Romito RR, De BP, Banerjee AK: Characterization of the in vitro system for the synthesis of mRNA from human respiratory syncytial virus. Virology 1993, 193:862-867.

13. Curran J: Reexamination of the Sendai virus $P$ protein domains required for RNA synthesis: a possible supplemental role for the $P$ protein. Virology 1996, 221:130-140.

14. De BP, Galinski MS, Banerjee AK: Characterization of an in vitro system for the synthesis of mRNA from human parainfluenza virus type 3 . J Virol 1990, 64:1135-1142.

15. Cattaneo R, Rebmann G, Schmid A, Baczko K, ter Meulen V, Billeter MA: Altered transcription of a defective measles virus genome derived from a diseased human brain. EMBO J 1987, 6:681-688.

16. Plumet S, Gerlier D: Optimized SYBR green real-time PCR assay to quantify the absolute copy number of measles virus RNAs using gene specific primers. J Virol Methods 2005, 128:79-87. 
17. Plumet $S$, Duprex WP, Gerlier D: Dynamics of viral RNA synthesis during measles virus infection. J Virol 2005, 79:6900-6908.

18. Bailey D, Chard LS, Dash P, Barrett T, Banyard AC: Reverse genetics for peste-des-petits-ruminants virus (PPRV): promoter and protein specificities. Virus Res 2007, 126:250-255.

19. Mitra-Kaushik S, Nayak R, Shaila MS: Identification of a cytotoxic T-cell epitope on the recombinant nucleocapsid proteins of Rinderpest and Peste des petits ruminants viruses presented as assembled nucleocapsids. Virology 2001, 279:210-220.

doi:10.1186/1743-422X-9-302

Cite this article as: Yunus and Shaila: Establishment of an in vitro

transcription system for Peste des petits ruminant virus. Virology Journal 2012 9:302

\section{Submit your next manuscript to BioMed Central and take full advantage of:}

- Convenient online submission

- Thorough peer review

- No space constraints or color figure charges

- Immediate publication on acceptance

- Inclusion in PubMed, CAS, Scopus and Google Scholar

- Research which is freely available for redistribution 